CATALAN REVIEW

Catalan Review

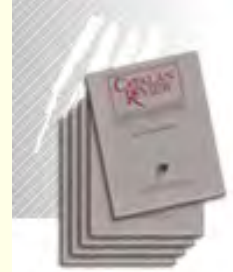

You are accessing the Digital Archive of the Catalan Review Journal.

By accessing and/or using this Digital Archive, you accept and agree to abide by the Terms and Conditions of Use available at http://www.nacs-

catalanstudies.org/catalan review.html

Catalan Review is the premier international scholarly journal devoted to all aspects of Catalan culture. By Catalan culture is understood all manifestations of intellectual and artistic life produced in the Catalan language or in the geographical areas where Catalan is spoken. Catalan Review has been in publication since 1986.
NORTH

AMERICAN

CATALAN

SOCIETY
Esteu accedint a l'Arxiu Digital del Catalan Review

A l' accedir i / o utilitzar aquest Arxiu Digital, vostè accepta i es compromet a complir els termes i condicions d'ús disponibles a http://www.nacs-

catalanstudies.org/catalan review.html

Catalan Review és la primera revista internacional dedicada a tots els aspectes de la cultura catalana. Per la cultura catalana s'entén totes les manifestacions de la vida intel lectual i artística produïda en llengua catalana o en les zones geogràfiques on es parla català. Catalan Review es publica des de 1986.

\title{
La correspondència entre Josep Pla i l'Editorial Joventut i les decisions editorials de Pla als anys $\mathbf{4 0}$ Lluís Quintana Trias And Mònica Baró
}

Catalan Review, Vol. XIX, (2005), p. 285-314 


\title{
LA CORRESPONDENNCIA ENTRE JOSEP PLA I L'EDITORIAL JOVENTUT I LES DECISIONS EDITORIALS DE PLA ALS ANYS 40
}

\author{
LLUISS QUINTANA TRIAS \\ MONNICA BARÓ
}

\section{ABSTRACT}

Immediately after the Civil War, Josep Pla took some decisions-not merely aesthetic, but also commercial - about his work that would lead him to publish his books with five different publishers. This article provides an explanation for these decisions, supported by unpublished correspondence between Josep Pla and the Editorial Joventut (see appendix) and the recently-published correspondence between Pla and Cruzet.

\section{INTRODUCCIÓ}

$U_{n}$ mer repàs als llibres publicats per Josep Pla immediatament després de la Guerra Civil permet adonar-nos que apareixen en cinc editorials diferents, a part de les edicions de bibliófil (Annex I). Estudiar els motius per què Pla hi oscil.la fins que no es decanta per una d'elles és el que ens proposem fer en aquest article, amb el suport de la correspondència inèdita entre Josep Pla i l'Editorial Joventut. La seva anàlisi, juntament amb la de la correspondència recentment publicada de $\mathrm{Pla}$ amb Cruzet, ens ha d'ajudar a entendre les decisions (no només estètiques) que pren Josep Pla sobre la seva obra en la immediata postguerra.

\section{J. ZENDRERA I L'EDITORIAL JOVENTUT}

Fundada el 1923 per un grup de particulars provinents del món del llibre i del periodisme, l'editorial Joventut ha mantingut una activitat ininterrompuda fins al moment actual. La seva trajectòria ha estat marcada per l'obra i la personalitat de l'editor Josep Zendrera que, poc després de la seva fundació, es féu amb la propietat del negoci i que, més endavant, comptà amb la col-laboració dels seus fills. Ha estat precisament el caràcter familiar d'aquesta institució allò que ha permès de conservar bona part del seu arxiu, a partir del qual es pot reconstruir el funcionament del negoci editorial d'aquesta casa, tant els aspectes més tècnics i de gestió 
com la relació de l'empresa amb el món cultural de l'època. En aquest sentit, les dades més valuoses provenen de l'arxiu de correspondència que es conserva complet a partir de i952. Per a les dates compreses entre 1923 i 1947 es disposa d'un volum considerable de documents, sense que puguem determinar-ne l'exhaustivitat. D'entre el volum de la correspondència destaca especialment aquella que va relacionar Zendrera i els seus col-laboradors més propers (com Marià Manent, que, a partir de 1942 i fins a la seva jubilació hi exerceix de director literari) amb els autors de l'empresa o de fora, i personalitats del món cultural, de Catalunya i de la resta de l'Estat, que tant va canviar durant la dilatada existència de l'editorial. Una altra font indispensable és constituïda per l'arxiu de contractes, que recull, en diverses sèries documentals que es complementen, la naturalesa de les relacions juridiques establertes entre l'editorial i els seus col-laboradors. Donada l'amplitud del marc legal que, durant molt de temps, ha regulat l'activitat editora al nostre país, $s^{3}$ expliquen les casuístiques tan particulars d'aquests contractes $i$ que, en general, els redactats i les clàusules variin molt d'un document a l'altre.

\section{JOVENTUT, EDITORA DE LLIBRES EN CATALÅ}

La relació entre Josep Pla (1897-1981) i l'editorial Joventut, ni que sigui de manera circumstancial, es pot seguir documentalment en els dos arxius esmentats. D'una banda, es conserven a l'editorial alguns contractes, rebuts i liquidacions que estableixen la relació indispensable entre l'autor $i$ l'empresa $i$ en determinen les condicions. D'altra banda, aquestes informacions, normalment escrites en castellà, es complementen amb la correspondència mantinguda entre Zendrera i Pla. Es tracta d'un conjunt de cartes comercials i personals (escrites en català o en castellà, segons les circumstàncies) que s'allarguen més enllà del període contractual. Malauradament, a l'editorial no es disposa de les cartes que, en ambdós sentits, degueren circular entre 1946 (data en què es degueren establir els contactes per a la publicació del primer llibre de Pla que edita Zendrera: Cadaqués) i 1952, data de les primeres mostres epistolars conservades a l'editorial, en què es fa esment d'una relació anterior. Potser la consulta d'altres arxius personals ens permetrà reconstruir la correspondència desapareguda.

Els documents que relacionen Pla amb l'editorial Joventut abasten des de 1947 , data de la publicació de Cadaqués, fins a 1980, un any abans de la mort de l'autor. Aquests documents ofereixen un doble interès. D'una banda, donen a conèixer alguns aspectes del món editorial des del final de la Guerra Civil fins als anys 6o: el tipus de contractes, els preus... De l'altra, especialment les cartes, ens permeten una visió nova d'un aspecte encara poc conegut de l'obra de Pla: la seva obra publica- 
da a Joventut, especialment en castellà. A més, ens mostren la peculiar relació gairebé simultània que va establir Pla amb tres editorials: Joventut, Selecta i Destino, i els conflictes que això va originar.

L'editorial Joventut, que en els seus inicis publica únicament en llengua castellana, absorbeix a partir de 1930 l'editorial Mentora que, tot i mantenir una línia d'edicions en castellà, es dedicava preferentment a la publicació d'obres en llengua catalana, adreçades tant al públic infantil com al públic adult. A partir d'aquest moment, i fins al final de la guerra civil, Joventut publicarà indistintament en ambdues llengües, tot i que no de manera sistemàtica $i$, sovint, tot conservant el peu d'impremta de Mentora en moltes edicions aparegudes amb posterioritat a la data de 1930.

L'adveniment del nou règim sorgit de la guerra civil implicà la restricció, quan no la prohibició, de publicar i fer circular obres en llengua catalana. En un primer moment, les edicions en català són prohibides, almenys fins a 1943, quan es permet la publicació de Verdaguer en versió prenormativa. A partir de 1946 es detecta una certa obertura pel que fa a les publicacions en català, $\mathrm{i}$ Zendrera - potser a instàncies de Marià Manent - intenta recuperar les edicions en català.

Així el setembre de 1946 és aprovada la publicació de l'obra $E l_{s}$ ocells amics, de Josep M. de Sagarra, que es publicarà el 1947. El permís d'edició d'aquesta obra s'explica, en part, per la personalitat de l'autor i per les coneixences que aquest tenia en el món intellectual del nou règim. Se'n va fer una edició de bibliòfil, edicions que en aquell moment gaudien de major permissivitat per la seva reduida difusió a causa de les limitacions de tirada i, també, del preu (Gallofré i Virgili 355).

Però les directrius de censura sovint eren canviants $i$ contradictòries i, per evitar els problemes derivats d'una prohibició a posteriori, alguns editors miraren de minimitzar els efectes d'aquestes arbitrarietats. Així, al 1947 Zendrera és un dels tres editors -juntament amb Aymà i Cruzet- que remeteren al Director general de Propaganda un llistat d'autors, els considerats "millors", que mereixien ésser publicats en vernacle (Gallofré i Virgili 299-309). Tot i que aquesta llista no s'ha trobat, cal suposar que rebé el vistiplau dels organismes censors i també cal suposar que Josep Pla en formava part. De fet, Pla era un dels autors que més beneplàcits rebia de les noves autoritats, que lògicament emeten al 1947 un veredicte favorable a la publicació de Cadaqués (Gallofré i Virgili 273), la qual cosa explicaria que Zendrera s'arrisqués a publicar una segona obra de Pla, Cartes de lluny, abans d'obtenir el preceptiu permís. Efectivament, l'edició porta peu d'impremta de 1947 tot i que la sol-licitud de permis es presenta al $1948 .^{1}$

1. Ministerio de Educación Nacional. Subsecretaria de Educación Popular. Sección de inspecciones de libros. Exp. 4290-48. Nota sense signar: "comprobación: sin antece- 


\section{L'ELECCIÓ DE SELECTA}

Partim d'una constatació: a partir dels seus primers llibres publicats després de la Guerra, Pla és un èxit de vendes en castellà, com ho demostren Viaje en autobuis o Guía de la Costa Brava, que el 1948 ja portaven tres edicions cadascuna. Això també ho veuen els editors i per això se'l disputen: Cruzet, de l'editorial Selecta, li proposa editar les seves obres completes (C_I_22/2/1946); ${ }^{2}$ Zendrera li demana $\left(Z_{2} 23 / 5\right)$ 1947) "ser el seu editor i enfocar la publicació de les seves obres amb una certa periodicitat", $i$ els de Destino també insisteixen ( $C_{-36} 3$ / 4/1948). Pla, d'entrada, no diu mai que no: fins i tot, el 1947, arriba a firmar un contracte d'edició exclusiva amb Zendrera, que no respecta mai, d'altra banda. Però a la llarga no accepta cap d'aquestes ofertes, ni la de Cruzet ni la de Zendrera ni la de Destino, segons afirma en una carta al primer: "no puc entrar en una negociació sobre obres completes" ( $\left.\mathrm{C}_{-3} 6_{3} / 4 / 1948\right)$. Com que de moment només tenim accés a la correspondència amb els seus editors, no sabem exactament què es proposava Pla en aquests anys: probablement no es veu com un autor jubilat que reuneix només material publicat i sembla pensar més en termes d'edició sistemàtica que no pas d'obres completes, una hipòtesi que $\mathrm{M}$. Gustà havia avançat i que la publicació de la correspondència amb Cruzet referma.

Pel que es pot deduir de les seves actuacions durant la immediata postguerra, Pla està preocupat per trobar l'editor "definitiu" de la seva obra. Al començament, sembla dubtar entre dues editorials: Destino i Joventut. Per això treu llibres en castellà a Destino a partir de Historia de la II República (1940), però el juny de 1947 firma l'esmentat "contrato de exclusiva" per a obra catalana i castellana amb Zendrera, després d'haver-hi editat Cadaqués (març 1947). Alhora, fa provatures amb dues altres editorials: en castellà, Argos (Las ciudades del mar, 1942), dirigida per Ignasi Agustí, que s'ha deslligat de Destino; i en catală, Selecta, la qual tempteja (març 1947) amb un llibre (Cartes de lluny) que acabarà editant Joventut (febrer i948). I fins i tot prova sort amb una cinquena editorial, Àncora, el primer número de la qual és precisament un llibre de Pla, Viatge a Catalunya (1946). De fet, Âncora sorgeix del grup de Destino però el projecte inicial sembla de $\mathrm{Pla}$, perquè $\mathrm{el}$ seu ideari correspon bastant al que després demanarà a Selecta. Aquest ideari el coneixem gràcies a una entrevista que, el febrer de 1947 ,

dentes; resultando: nada hay que oponer a la autorización de esta serie de impresiones de viaje por Europa, contada con buen estilo."

2. Citem cada carta indicant primer el destinatari $(C=$ Cruzer, $Z=$ Zendrera), després el número d'ordre dins de l'edició de l'epistolari (de l'edició de la correspondència entre $\mathrm{Pl}_{\mathrm{a}}$ i Cruzet feta per Gallofrế, o de la nostra) i finalment la data. 
li fa a Destino un misteriós X (que té tot l'aspecte de ser un invent de l'entrevistat), on Pla desmarca Àncora de l'editorial que publica el semanari, insisteix en l'enfocament monolingüe del nou projecte i mostra el seu interès per publicar "escritores vivos, jóvenes, luchadores" (X). Però Àncora no prospera.

Durant el 1948, Pla dubta entre Selecta i Joventut per a l'obra en català: signa un contracte per Girona amb Joventut (octubre), i envia a Cruzet material per a Coses vistes (desembre). Per a l'obra en castellà, en canvi, sembla decidit per Destino, com es pot comprovar per la regularitat amb què hi segueix publicant.

El 1949 sembla decidir-se per Selecta $\mathrm{i}$ deixa de col-laborar amb Joventut. Tot i que no respecta el contracte d'edició exclusiva amb Joventut i publica en castellà a Destino i en català a Selecta, Joventut no sembla ressentir-se'n fins al 1952, quan veu aparèixer Girona i reacciona avisant Destino (no tenim constància que avisi també Selecta) que Girona, com Cadaqués i Cartes de lluny, pertanyen a Joventut. Finalment, Selecta acabarà comprant Cartes de lluny a Joventut, però no podrà recuperar mai Cadaqués, com consta en una carta de Pla a Albert Manent de 13/4/1959 (Manent, "Vuit cartes" 75). El tancament de l'afer ocupa nombrosa correspondència a partir de desembre de 1952 tant amb Cruzet com amb Zendrera. (Per a tot aquest episodi, vegeu també Quintana Trias, "Un manuscrit".)

Les raons per les quals Pla dubta entre les editorials són evidents quan comprovem les xifres tant de tiratge com d'avançaments (Annex 2). Recordem que una preocupació fonamental en Pla és la professionalització de l'escriptor i la seva responsabilitat en el control de la difusió de la seva obra i en la consideració de la feina dels altres professionals: editors, distribuïdors, etc (Quintana Trias, Un manuscrit 219). És previsible, doncs, que es mirés aquestes xifres amb almenys la mateixa atenció que nosaltres. Zendrera paga millors avançaments que Selecta (8.000 ptes. contra 6.000). Els llibres també són més cars: 40 ptes. per Cadaqués contra 30 o 35 de l'edició rústica de Selecta. El tiratge, en canvi, és igual a les dues editorials: 2.000 exemplars, com també és igual el percentatge de l'autor: $10 \%$. A l'hora de decantar-se per Selecta, hi pesen diversos factors.

I) Trajectoria estètica. Selecta, l'empresa de Cruzet, continua la de López Llausàs, l'editor de Pla des de 1929 fins a la Guerra Civil (Gustà, Els origens 411 ), i per tant és dipositària d'aquesta part de la seva obra. Potser al principi Pla pensava encara exhaurir-ne les existències, perquè al verso de la pàgina de respecte de Humor honesto y vago editada a Destino el I942, sota l'epígraf "Algunas obras del autor" encara hi fa constar "Cartes meridionals" i "Relacions", ambdós anteriors a 1936, però en els llibres següents ja no ho repeteix. Als anys 40 , aquesta obra en català no té sortida per problemes amb la censura, però és que, a més, 
Pla la considera obsoleta i la vol aprofitar per reescriure la seva obra, un procediment que caracteritza la seva producció de després de la guerra i que ha estat prou estudiat (Quintana Trias, Josep Pla 531). Editar amb Selecta li permet doncs comprar, a compte dels seus drets d'autor, llibres obsolets que vol impedir que surtin al mercat (Gallofré Virgili 20).

2) Perspectives comercials. Els llibres de Joventut no es venen bé: en gairebé 4 anys, només ha venut zro exemplars de Cartes de lluny i, per a Cadaqués, les vendes no van millor, cosa que es confirma quan veiem que quinze anys després de la seva sortida encara no està exhaurit. Pla, com ja hem dit, té molt present que la seva obra és un èxit de vendes i que, per tant, si alguna cosa falla, no és pas la seva obra: "El senyor Zendrera és un gran editor en castellà; en català, com vosté observa, no és res" (C_220_18/12/1952). Les previsions de Pla es confirmen: a Selecta, els seus llibres es venen molt bé, fins a límits sorprenents, com en el cas de Girona, del qual ha venut més de la meitat de l'edició en només dos mesos.

3) Afinitats ideològiques. Cruzet té un projecte editorial diferent al de Destino i al de Joventut perquè el seu és un projecte monolingüe català. Això és el que busca Pla, i per això promet sovint que no escriurà més en castellà. A l'esmentada carta a Manent de 13/4/1959, Pla comenta que la fórmula bilingüe només té justificació en la immediata postguerra, però no després. Això podria explicar el fracàs dels seus llibres a Joventut, una editorial solvent dirigida per un professional de gran experiència. Per a Pla, l'única manera d'editar en català és crear un públic estable amb uns productes dignes en un mercat normal a través d'una empresa identificada amb el projecte. Ell hi porta la seva part com a professional implicat, i es preocupa de controlar el tiratge (que demana pujar de 2.000 a 3.000), la qualitat del producte, els colors de la coberta i fins les dates en què ha de sortir el llibre. Per això rebutja l'edició de llibres de luxe (C_189_25/9/1952), habitual a la postguerra (Manent, "Els llibres" 321). Més interessant, des de la nostra perspectiva, és la denúncia dels qui no volen implicar-se en aquest model; per això critica enèrgicament el derrotisme que practiquen els franquistes desenganyats (com el cas de Mateu, C_215_27/9/1952) i, especialment, el conformisme d'alguns catalans davant la prostració de la llengua, com el cas d'Alberto Puig Palau (C_I6I_4/5/1952). Entengui's bé que l'enfrontament de Pla amb ells, o l'afinitat amb Cruzet, no se situa en l'àmbit de l'antifranquisme ni, probablement, en el del catalanisme. Políticament, és molt més a prop d'un Mateu que no pas dels escriptors de l. clandestinitat i, no cal dir-ho, de l'exili. A manca d'un estudi complet de l'evolució ideològica de Pla durant la postguerra, podem entreveure, a través dels seus comentaris, que ell no es planteja pas escriure en català com una eina més dins d'un projecte polític (la lluita contra la dictadura). Igual que els autors de la clandestinitat i els de l'exili, participa 
d'una manera tenaç en el projecte de recuperar la literatura catalana, però la seva no és una maniobra tàctica, còmplice amb d'altres que s'estan fent des de diversos angles; la seva participació en la "represa", tal com es deia en el llenguatge de l'època, és fonamental, però caldria esbrinar si tothom (i ell mateix!) ho va veure aixi.

\section{LA CORRESPONDÉNCIA ENTRE JoSeP PLA I L'EDITORIAL. JOVENTUT ${ }^{3}$}

\section{1. $(16 / 1 / 1947)$}

[Contracte entre Editorial Juventud i Josep Pla]

"Entre Don José Pla, con domicilio en Llofriu, Palafrugell (Mas Pla), - llamado en este contrato EL AUTOR-, por una parte, y Don José Roch, con domicilio en Barcelona, calle de Valencia, 617 y la Editorial Juventud S.A., con domicilio en la misma ciudad, calle de Provenza ror - llamados en este contrato EL EDITOR - por otra parte, se conviene lo siguiente:

$1^{\circ}$. El Autor concéde al Editor el derecho exclusivo de publicación de su libro 'CADAQUÉS' en sus ediciones catalana y castellana.

$2^{\circ}$. El Autor recibirá a la firma de este contrato la cantidad de ocho mil pesetas (Ptas.8.00o.-), equivalente al 10\% del precio de venta del libro en su primera edición, en catalán, de 2.000 ejemplares a 40' (sic) pesetas.

Para las ediciones sucesivas el Editor satisfará al Autor el to\% sobre el precio de venta, que se pagará por anticipado al ponerse a la venta cada edición.

$3^{\circ}$. Una vez agotada la primera edición catalana, el Editor podrá optar entre hacer una segunda edición en la misma lengua o editar la obra en castellano.

$4^{\circ}$. De la primera edición catalana se hará una tirada, numerada, de roo ejemplares en papel de hilo, de la que se abonará al Autor el $10 \%$ sobre el precio de venta, mediante liquidaciones anuales.

$5^{\circ}$. Se reservarán gratuitamente al autor 12 ejemplares de las ediciones corrientes y 2 ejemplares de las ediciones en papel de hilo.

$6^{\circ}$. Si la obra objeto del presente contrato queda agotada durante un período de seis meses y, previa notificación del Autor, el Editor no publica una nueva edición en los seis meses siguientes, se considerará anulado el presente contrato y revertirán al Autor los derechos por él cedidos.

Firmado, por duplicado y a un solo efecto, en Barcelona a 16 de enero de 1947." el contrari.

3. Totes les cartes aquí publicades provenen de l'arxiu de Joventut si no s'especifica 


\section{2. $(3 / 5 / 1947)$}

[Carta de Zendrera a Pla $]^{4}$

[encapçalament Editorial Juventud, S.A]

$\mathrm{M} / \mathrm{M}$

3 maig 1947

Senyor Josep Pla

Mas Pla, LLOFRIU (Girona).

Distingit amic:

M'és grat confirmar-li el que vaig dir-li en la nostra recent conversa sobre projectes editorials, o sigui, que em plauria molt ser el seu editor i enfocar la publicació de les seves obres amb una certa periodicitat, en la forma que pugui resultar per a tots més avantatjosa. Si vostè ha tingut temps d'ordenar novament els seus originals, li estimaria? que em fes una llista dels llibres que creu aconsellable publicar en primer terme, així com dels que preveu per a una data més llunyana. Potser, amb motiu de la mort d'En Cambó, podria preparar ràpidament una nova biografia de l'il-lustre polític i protector de la cultura; un llibre més breu que la biografia que vostè va escriure anys enrera, però aprofitant, naturalment, la seva copiosa documentació i enfocant la tesi a la llum dels esdeveniments posteriors. Un llibre així crec que podria tenir èxit; li sembla que la Censura el permetria?

Tal com vaig significar-li en la nostra última entrevista, serà per a mi un gran plaer d'establir una intensa col-laboració editorial amb vostè i amb el nostre amic Sr. Roch, l'activitat del qual en aquests afers resultarà molt útil, com ha demostrat en vetllar acuradament el seu CADAQUÉS, llibre que ha plagut molt a tothom.

Espero, doncs, les seves notícies i desitjo celebrar nous canvis d'impressions amb vostè $i$ amb l'amic Roch sobre els nostres projectes.

Cordialment el saluda el seu affm. amic,

Josep Zendrera

\section{3. $(22 / 6 / 1947)$}

[Rebut manuscrit de Josep Pla]

[Encapçalament de l'Editorial Juventud, S.A.]

"He recibido de Editorial Juventud, S.A. la cantidad de Pesetas Diez mil, a cuenta de mis derechos de autor de mis libros preteritos (sic) y futuros, en catalan (sic) y en castellano, segun (sic) contrato de exclu- 
siva durante un plazo de cinco años, a firmar, con todas las puntualizaciones de los libros disponibles, antes del 30 de junio actual.

Cadaqués veintidos de junio de 1947. José Pla"

\section{4. $(27 / 9 / 1948)$}

Document oficial del "Cuerpo facultativo de archiveros, bibliotecarios y arqueólogos" amb la inscripció de "Cadaqués. Fotografías de José Ferrés. Xilografías de C. Ricart" de l'autor "José Pla Casadevall" en el registre general, amb data 27 d'abril de 1947 i el número de registre 25906. S'indica que la tirada és de 2.100 exemplars i que la data de publicació és el 30 d'abril de 1947. La inscripció és del 27 de setembre de 1948. El document és una còpia del 3 de febrer de 1953

\section{5. $(31 / 12 / 1949)$}

[Liquidació de drets d'autor d'Editorial Joventut a Pla.]

[Encapçalament de l'Editorial Juventud. S.A.]

"31 diciembre 1951

Primera liquidación de ventas de 'CARTES DE LLUNY', de JOSÉ PLA.

Tirada

Existencia en 31-12-5I

[Venuts]

$$
\begin{aligned}
& 2000 \text { ejs. } \\
& \frac{1740 " 1}{260 "}
\end{aligned}
$$

A deducir autor y propaganda so " [" per indicar repetició] [Total venuts]

$$
=210^{\prime \prime}===
$$

210 ejs. a $20^{\circ}-\left(50 \%\right.$ s/. $\left.40^{\prime}\right) \quad 4.200^{\circ}$

Coste edición

$\begin{array}{lr}\text { Autor } & 8.000,- \\ \text { Revisión } & 1.000,- \\ \text { Dos xilografías } & 430,- \\ \text { Papel texto } & 7.938,- \\ \text { Papel cubierta } & 500,- \\ \text { Papel cebolla } & 500,- \\ \text { Tirada texto } & 6.800,- \\ \text { Tirada cubiertas } & 300,- \\ \text { Encuadernación } & 2.100,- \\ & ====-\end{array}$

Autor

Revisión

Dos xilografias

Papel texto

Papel cubierta

Papel cebolla

Tirada texto

Encuadernación

(No hay beneficios por no haberse cubierto aŭn el coste de la edición) Sr. D. José Rach

Ciudad." 


\section{6. $(5 / 12 / 1952)$}

[Carta mecanografiada de Josep Zendrera a Josep Pla.]

"5 desembre 1952

Sr. Josep Pla

Mas Pla,

Llofriu.

\section{Distingit amic,}

Amb gran sorpresa $\mathrm{i}$ disgust he vist publicat per un altre editor el seu llibre Girona, que vostè ens havia cedit en exclusiva (per al català i el castellà) segons contracte del 30 d'octubre de $1948,{ }^{6} \mathrm{~d}^{\prime}$ acord amb la $2^{\mathrm{a}}$ clàusula del qual vam satisfer-li 2.000 pessetes a compte dels drets d'autors.

Ja recordarà que ens havia lliurat gran part de l'original, i que vam tornar-li-ho, a petició de vostè, perquè pogués completar-lo i deixar-lo llest per a la impremta. El Sr. Roch, en nom meu, li ha demanat repetidament el llibre: la darrera vegada va ser el passat setembre. No puc, doncs, atribuir a una falla de la memòria una decisió que no sé com explicar-me donada la nostra antiga amistat i les relacions d'afers que haviem tingut darrerament. ${ }^{7} \mathrm{He}$ de confessar-li, amic $\mathrm{Pla}$, que aquest aspecte, més que el purament material, em fa la sorpresa especialment dolorosa. La cordialitat que ha informat sempre els nostres tractes no feia preveure una decisió que només s'explicaria si podia atribuir-se a un moment de lamentable oblit.

Li prego que vostè mateix em suggereixi una fórmula per arreglar l'anòmala situació creada, i em repeteixo el seu affm. amic,

Josep Zendrera."

\section{7. $(7 / 12 / 1952)$}

[Carta mecanografiada sense firmar de Josep Pla a Josep Zendrera.]

"Palafrugell, ro desembre r952

Sr. En J. Zendrera

Barcelona

\section{Distingit amic:}

He rebut la seva del dia 5, que agraeixo.

La seva carta m'ha sorprès. De la lectura objectiva i desapassionada dels dos contractes firmats amb vostè, no es desprèn en cap moment l'obligació per part meva de oferir-li el llibre 'Girona'. Ni en el con-

\footnotetext{
5. Es refereix a la edició publicada per Selecta l'any 1952.

6. No tenim còpia d'aquest contracte.

7. L'última "relació d'afers" de Pla amb l'editorial era Cartes de lluny, de 1948.
} 
tracte amb el Sr. Roch sobre 'Cadaqués', ${ }^{8}$ ni el firmat amb vostè sobre 'Cartes de lluny'9 es fa cap al-lusió a aquesta obligació. En la llista d'obres que figuren al peu del contracte de $30 / 6 / 1947,{ }^{10}$ no hi figura el nom d'aquest llibre.

El contracte de 30/6/i947 es pot considerar d'exclusiva. Però aquesta exclusiva, com el document estableix explícitament, fou donada per 5 anys a partir del $30 / 6 / 47$, per tant, la duració ha expirat sobradament. Jo no hauria donat a un altre editor el dret d'editar un llibre gravat amb un contracte d'exclusiva.

Ara be?: de la mateixa manera que l'obvietat d'aquestes consideracions és manifesta, un deute de correcció m'obliga a constatar el fet de les converses tingudes amb el Sr. Roch sobre el "Girona" i el desplaçament momentani de l'original de les mans meves a les mans d'ell $i$ el seu interès per tenir el llibre. Per altre part, tinc la seva amistat en prou apreci perquè em consideri obligat a eliminar de la nostra relació, tot el que pugui perturbar-la. En aquest sentit i fent-me càrrec de l'obligació merament moral concreta, estic disposat a proposar una solució. Jo li donaré 2000 ptes. i vostè em farà si li plau arrivar to exemplars del 'Cadaqués' i un número d'exemplars de 'Cartes de lluny' el preu dels quals - amb el descompte habitual que fa als llibrers, el $25 \%$ - cobreixin les 2000 ptes. $^{\text {II }}$

Quedo de vostè affm. amic is.s.

q.e.l.s.m."

8. $(12 / 12 / 1952)$

[Carta mecanografiada, sense firmar de l'editorial a Josep Pla.]

"I2 diciembre 1952

Sr. D. José Pla

Palafrugell (Gerona)

Distinguido señor nuestro:

Acaba de llegar a nuestras manos su carta mecanografiada del ro actual que, por cierto, ha venido sin firmar.

8. És el contracte indicat al document $Z_{-} I_{-} 16 / 1 / 1947$.

9. No tenim còpia d'aquest contracte.

10. No tenim constància d'aquest contracte.

11. Segons Z_1_16/1/1947, Cadaqués es venia a 40 ptes. l'exemplar Segons $Z_{-5} 3 \mathrm{t} / 12 / 1949$, Cartes de lluny es venia també a 40 . Amb el descompte exigit, els dos se li havien de vendre a $30, \mathrm{i}$ l'editor li havia de remetre els so exemplars de Cadaqués i uns 57 exemplars de Cartes de lluny [(30 ptes. $x$ to exemplars de Cadaqués) + (30 ptes. $x 57$ ex. de Cartes...) = 2.010 ptes.]. A partir d'aquí, aquesta qüestió serà tractada en la correspondència paral-lela de Pla amb Cruzet: cf. C_220_18/n1/1952 i tot l'any 1953. 
Independientemente de los dos contratos a que Vd. hace referencia, existe un tercer contrato. Ya le decíamos a Vd. bien claramente en nuestra carta del 5 diciembre que existe un contrato de 30 octubre de 1948 que trata exclusivamente del libro 'Gerona', ${ }^{12}$ y en el que nos da Vd. la exclusiva de publicación de este libro en catalán y en castellano. Asimismo se le pagaron a Vd. 2.000 ptas. a cuenta de los derechos de publicación de dicha obra. Debe Vd. buscar el mencionado contrato; si no lo encuentra, ya le mandaremos nosotros fotocopia del mismo. Nosotros le hablamos concretamente de una cosa y Vd. en su contestación nos habla de otras. Hemos de mantener, pues, integramente cuanto le decíamos en nuestro escrito del 5 de diciembre. ¿Es que ha vendido Vd. también los derechos castellanos del mencionado libro? Mejor será que nos hable Vd. francamente para saber a qué atenernos.

Esperan sus noticias sus affmos. ss. ss.

q.e.s.m"

\section{9. $(15 / 12 / 1952)$}

[Carta mecanografiada, sense firmar de l'editorial Joventut a l'editorial

Destino.]

"Certificado

Is diciembre 1952.

Ediciones Destino,

Pelayo, 28,

Barcelona.

Distinguidos Colegas:

Nos permitimos hacer saber a Vds., a los efectos consiguientes, que tenemos firmados con el escritor José Pla contratos de edición exclusiva, en catalán y en castellano, sin fecha de caducidad, de los siguientes libros: CADAQUÉS

\section{CARTES DE LLUNY}

GIRONA.

Hacemos esta advertencia porque el autor ha autorizado otra edición del libro GIRONA, obra de la que tenía firmado contrato con nosotros desde hace varios años, habiendo ya cobrado una cantidad a cuenta de sus derechos de autor. El original del libro obraba ya en nuestro poder y nos fué retirado por el autor con el pretexto de que iba a corregirlo y ampliarlo.

Creemos un deber de compañerismo hacer esta advertencia en evitación de nuevas ventas duplicadas de derechos de edición.

Nos reiteramos de Vdes, attos. y s. s.,"

12. Tot i el títol en castellà, s'està referint a l'edició catalana publicada per Selecta. 
10. $(28 / 12 / 1952)$

[Carta manuscrita firmada de Josep Pla a Josep Zendrera] $]^{13}$

"Palafrugell $28 / 12 / 52$.

Sr. D. J. Zendrera

Barcelona

Muy Sr mío: Le ruego no conceptue una desconsideración el hecho de que mi contestación a su carta llegara sin firma. Fué un error de la persona encargada de echarla al correo.

También le ruego perdone el retraso de la presente imputable a la necesidad de encontrar, en el desorden de cuatro años de papeles, el contrato a que hace $\mathrm{Vd}$. referencia. Aun a riesgo de aumentar mi fama de desordenado, debo decirle, como una mera constatación, que mis esfuerzos no han tenido éxito: no he logrado dar ni con el contrato aludido, ni con otros dos contratos que el Sr. Roch ha tenido la amabilidad de señalarme, puesto que los contratos fueron cinco. ${ }^{14}$

Ello no prejuzga el fondo de la cuestión. El hecho es imputable al desorden agravado por el paso del tiempo. Creo que podría también ser permitida la hipótesis de que las copias de los documentos no me fueron enviadas - cosa que a veces puede suceder aun a las oficinas mejor organizadas. Todo esto es sin embargo secundario y solo habrá servido para que mi carta anterior fuera de una precipitación notoria por la que le pido todas mis excusas.

No se moleste mandándome una copia fotográfica de los documentos, puesto que reconozco su existencia.

Ignoro si en estos contratos se prevé el procedimiento a seguir en caso de desacuerdo. Si considera Vd. que ha habido incumplimiento de contrato me atengo al procedimiento establecido y en todo caso a su equidad reconocida.

Queda de Vd. affm. s.s. q. e. s. m.

Jose Pla"

13. Pla recull $i$ accepta el canvi de llengua,

14. De moment portem comptats quatre contractes (tres llibres: Cadaqués, Cartes de llany i Girona, més el contracte d'exclusivitat), dels quals només tenim cópiå d'un: Cadaqués (document 1 ). No entenem, doncs, els comptes de Pla. 
II. (/I/1953)

[Carta manuscrita firmada de Josep Pla a Josep Zendrera]

"Palafrugell, gener i953

Sr. D. Josep Zendrera

Barcelona

Molt apreciat amic: He rebut el seu Cristmas acompanyat del present mes valuós que podria fer-me: el llibre sobre Roma de Labande. ${ }^{15} \mathrm{M}$ 'ha semblat un literal prodigi editorial, una obra perfecte.

La setmana que ve faré un article al 'Diario de Bar'na', sobre el Roma. Com que en aquests diaris, hi ha el criteri que de llibres només en poden parlar els crítics, li prego de demanar al Sr. Castillo (Albert o Enric) que deixin passar el meu article.

Feia molts de mesos que no havia tingut a la ma, un llibre editat aqui de tanta categoria editorial i d'una bellesa tan sorprenent.

Passi, vosté i la seva familia un any de salut i prosperitat.

Rebi l'agraiment del seu aff. vell amic

Josep Pla"

12. $(23 / 1 / 1953)$

[Carta mecanografiada firmada de Josep Zendrera a Josep Pla]

"23 gener 1953.

Sr. Josep Pla

Mas Pla,

LLOFRIU, Palafrugell.

Molt apreciat amic:

He rebut les seves dues últimes cartes i li agraeixo els seus auguris d'Any Nou, als quals correspon ben cordialment. Moltes gràcies, també, per l'amable al-lusió que fa aquesta Editorial en el magnífic article publicat ahir al 'Diario de Barcelona'. ${ }^{16}$

Per al seu arxiu li adjunto una còpia fotogràfica del contracte sobre el llibre GIRONA. ${ }^{17}$ L'amic Roch i jo tenim la idea que vostè va signarlo en una entrevista i en aquella ocasió va ser-li lliurat l'exemplar que li corresponia.

15. Y. y E. R. Labande. Roma. Barcelona: Joventut, 1952. Colección Bellos Países. 140 ptes. (Editat l'abril de 1952).

16. Es tracta d'una ressenya intitulada "Roma" publicada el 22 gen. 1953 a la columna setmanal que tenia Pla al Diario de Barcelona.

17, Contra el desig expressat per Pla Z_10_28/12/1952: "No se moleste mandándome una copia fotográfica de los documentos, puesto que reconozco su existencia." 
Amb el desig de resoldre amistosament aquest afer, vaig fer unes propostes al Sr. Cruzet a finals de desembre. Li deia que estaríem disposats a renunciar als drets de GIRONA i de CARTES DE LLUNY a canvi que ell ens adquirís la resta d'existències d'aquest darrer llibre. ${ }^{18}$ No he rebut encara la resposta, però penso que aviat reprendrem les converses amb el Sr. Cruzet i tinc l'esperança que, tots plegats, arribarem a trobar una fórmula viable.

Ben cordialment el saluda el seu affm. amic.

Josep Zendrera"

\section{3. (11/2/1953)}

[Carta mecanografiada firmada de Josep Zendrera a Josep Pla]

"II febrer 1953.

Sr. Josep Pla

Mas Pla,

LLOFRIU, Palafrugell.

Benvolgut amic:

Com a continuació de la meva carta del 23 de gener, li comunico que ahir vaig oferir a un representant del $\mathrm{Sr}$. Cruzet una rebaixa del $15 \%$ sobre el preu de cost de la nostra existència de CARTES DE LLUNY, de manera que el total de 22.950'50 ptes., que és el cost dels llibres en rama i dels relligats, quedaria reduit a $19.456^{\circ}$ - A més, amb el desig de solucionar aquest afer, estic disposat a abonar-li 8.000 ptes. pels drets d'autor d'una edició castellana del seu CADAQUES. ${ }^{19}$ Restant d'aquesta suma les 2.000 ptes. que li tenim anticipades per GIRONA, el preu net del remanent de la nostra edició de CARTES DE LLUNY quedaria reduit a ptes. $13.546^{3}-$, que podria satisfer el Sr. Cruzet en 4 terminis.

Només venent-se 700 exemplars amb un benefici de 20 ptes. ja queda sobradament cobert el cost de l'actual existència de l'edició. Així, fins fent l'operació per compte de vostè, el Sr. Cruzet no trigaria a reintegrar-se de la quantitat avançada. Espero que estudiarà amb interès aquesta fórmula - que detallo al peu - i me'n dirà aviat alguna cosa.

Acabem de publicar PARIS en la col-lecció on va aparèixer el ROMA que ja coneix. Li envio un exemplar del nou llibre, juntament amb les primeres novel.les de Zweig (primer volum de les Obres completes) i ANNAPURNA de Maurice Herzog. Consti que li envio els llibres perquè sé que li plauen, i en cap moment ha de creure's obligat a comentar-

18. 1.896 exemplars, tal com consta $Z_{-13} \pi / 2 / 1953$.

19. En el contracte d'edició de Cadaqués (document 1), constava que Joventut tenia l'exclusiva en català i en castellà d'aquest llibre. D'altra banda, Joventut avançava a l'autor 8,000 ptes, en conceptes de drets d'autor, corresponent a un ro \% de la tirada. 
los. ${ }^{20} \mathrm{Ja}$ sap fins a quin punt ens complauen els seus articles sobre els nostres llibres, però no és pas per estimular-lo a escriure'n que de vegades li envio mostres de les nostres edicions. amic

Esperant les seves notícies, molt cordialment el saluda el seu affm.

998 exs. rama a 13's

698 " rell. a $44^{\prime}$

Rebaixa del $15 \%$

Drets ed. castellana

"Cadaqués", deduint

2..000 ptes de "Girona"

IMPORT NET

Josep Zendrera"
$13.223,50$

9.772,00

$22.995,50$

$3.449,50$

19.546,00

$6.000,00$

$13.546,00$

14. $(16 / 2 / 1953)$

[Carta manuscrita firmada de Josep Pla a Josep Zendrera]

" $16 / 2 / 53$

J.Pla

Mas Pla

Llofriu ${ }^{2 i}$

S. D. Josep Zendrera

Barcelona

Molt apreciat amic:

Tinc en el meu poder, les seves dues ultimes cartes, de $23 / \mathrm{t} / 53$ i de $\mathrm{II} / 2 / 53 .{ }^{22}$ La primera carta contenia una fotocopia del contracte sobre el 'Girona'.

Considero un deute elemental de correcció tornar-li les 2000 pts. que vosté m'avançava en el moment de la firma d'aquest contracte. ${ }^{23}$ Son diners cobrats inadequadament i que no em corresponen. Si els hagués pogut tornar abans, ho hagués fet.

20. Com acabem de veure (document II), Pla havia fet recentment una ressenya elogiosa de llibre Roma editat per Joventut.

2x. Membret imprès.

22. Z_12_23/1/1953 i Z_13_11/2/1953, respectivament.

23 Aquestes 2.000 ptes., que eren un avançament per a la publicació de Girona, han estat repetidament esmentades per Zendrera $\left(Z_{-} 6_{-} / 12 / 1952, Z_{-} 8_{-}{ }_{2} / 12 / 1952\right.$ i, sense especificar-hil la quantitat, $Z_{-9 \perp 5} / 12 / 1952$ ). 
Li demano que els accepti, perquè la seva acceptació no prejutja res. Els hi envio per 'Transportes Reunidos', de Palafrugell i li demano que m'acusi rebut. Si la meva situació de salut m'ho hagués permès, els hi hagués portat personalment.

L'acceptació d'aquests diners, no prejutja la negociació dels exemplars 24 de 'Cartes de lluny'. He reiteredament comunicat al Sr. Cruzet, perquè ho digués al Sr. Manent, que estic disposat a comprar un lot considerable d'exemplars d'aquest llibre si els termes de pagament no m'ofeguen. En aquest sentit li agraieixo molt l'esprit de la proposició continguda en la seva carta de $\mathrm{Ir} / 2 / 53$. Per l'edició de traduccions castellanes, ens entendrem sempre i no cal dir sobre la traducció de 'Cadaqués'.

No he rebut encara el 'Paris que em promet. En faré un article al 'Diario de Barcelona'. ${ }^{25}$ Moltes gràcies.

Saludi a la Sra. Zendrera, als seus fills, al Sr. Roch. ${ }^{26}$

Es sempre seu affm. amic i servidor Josep Pla."

\section{5. $(23 / 2 / 1953)$}

[Carta mecanografiada firmada.de Josep Zendrera a Josep Pla] " 23 febrer 1953.

Sr. Josep Pla

Mas Pla,

LLOFRIU, Palafrugell.

Estimat amic:

Amb la seva atenta carta del 16 vaig rebre la quantitat de 2.000.- pessetes, que li deixem abonades en compte. El corresponent rebut va ser entregat al recader.

Ja sap que, per al pagament dels exemplars de CARTES DE LLUNY, li donarem tota mena de facilitats. $\mathrm{Li}$ agrairé que m'indiqui quins terminis li interessa d'establir. Tal com vaig oferir-li un considerable descompte en el preu, em serà grat d'estudiar les seves suggerències sobre la forma de pagament, i estic segur que arribarem a un acord.

Esperant les seves notícies, sóc sempre el seu affm s. i amic, Josep Zendrera"

24. Fragment barrat, il-legible.

25. Vegeu Z_13_n/12/1953. Tant si Zendrera ho pretenia com si no, Pla interpreta que cal fer-ne una ressenya.

26. Primera menció de la familia de Zendrera, que Pla indubtablement coneixia de Cadaqués. 
16. $(3 / 6 / 1953)$

[Factura de l'editorial Joventut a Josep Pla.]

"Fecha, 3 de junio de 1953

A Sr. D. José Pla

LLOFRIU- Palafrugell (Gerona)

998 CARTES DE LLUNY (en rama)

$680^{27}$ CARTES DE LLUNY (encuadernados)

13 '25

14 '0o

Descuento $15 \%$

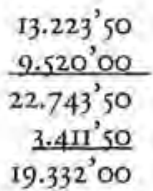

17. $(30 / 12 / 1953)$

[Carta mecanografiada de Josep Zendrera a Josep Pla] "30 diciembre 1953

Sr. D. José Pla

LLOFRIU (Gerona)

Mi distinguido amigo:

De conformidad con lo convenido en recientes entrevistas con don Tomás Garcés, he entregado a dicho señor los contratos relativos a las obras CARTES DE LLUNY y GIRONA (UN LLIBRE DE RECORDS), que quedan anulados. Le he entregado igualmente, por duplicado, los contratos referentes a la traducción castellana de diversas narraciones de su serie COSES VISTES, ${ }^{28}$ que publicaremos en dos tomos bajo el título ESTAMPAS DE LA COSTA BRAVA o uno de ellos con este título y el otro con ESTAMPAS DEL AMPURDÁN. Rogamos nos devuelva un ejemplar de los contratos ${ }^{29}$ debidamente autorizados con su firma. Al propio tiempo le comunico que deseamos editar en castellano su libro titulado Cadaqués. ${ }^{30}$

27. $A Z_{-} 13 \_11 / 12 / 1953$ eren 698 ; sorprenentment, de febrer a juny se n'han venut 18 . Per aixô les xifres es modifiquen lleugerament.

28. Es refereix a la sèric de sis llibres anomenats Coses vistes. El primer (Coses vistes, Primera sèrie. Barcelona: Selecta, 1949) era el llibre amb què Pla havia iniciat la seva relació amb Selecta, com ja hem comentat a proposit del document 3, i recollia, amb variants, un volum de 1925 amb el mateix títol. Els altres llibres eren Bodegó amb peixos (1950), L'illa dels Castanyers (1951), Pa i raïm (1951), El vent de garbi (1951) i Llagosta i pollastre (Sobre la cuina catalana) (1951). El setè volum de la sèrie, Contraban, és de 1954, posterior a la carta. Aquesta col. lecció de Selecta en què havien aparegut les obres de Pla era, en el primer format, in $16^{\circ} \mathrm{i}$ tapa dura; va canviar a in $8^{\circ}$ el 1956, amb el número $201 \mathrm{de} \mathrm{l}_{2}$ col-lecció, precisament el primer volum de les Obres completes de Pla.

29. De fet, es tracta d'un sol contracte per als dos toms de Estampas..., tal com rectificarà al final de la carta. Recordem que no li calia contracte per editar en castellà Cadaqués, perquè en tenia un de firmat de feia sis anys ( $\left.Z_{-1} 16 / 1 / 1947\right)$.

30. Vegeu supra, comentari a $Z_{13}$ 11/12/1953. 
Remito también al Sr. Garcés la factura relativa a las existencias de nuestra edición CARTES DE LLUNY, que, con el descuento convenido del I5\%, asciende a Ptas. 19.332.- Tenemos a disposición de Vd. las mencionadas existencias y a su entrega firmaremos el correspondiente recibo de su valor. Le rogamos nos devuelva firmados los recibos relativos a la edición castellana de CADAQUÉS y ESTAMPAS DE LA COSTA BRAVA (I y II).

Después de las operaciones aludidas, su estado de cuentas es el siguiente:

\section{Existencias CARTES DE LLUNY}

\section{Cargos Abonos}

Derechos de edición castellana CADAQUÉS

(I0\% sobre 2.000 ejs. a 40 ptas.) 8.000 ,- ptas.

-528 del $6,60 \%$ de utilidades ${ }^{31}$

Neto 7.472 ,

A cuenta derechos de edición castellana

ESTAMPAS DE LA COSTA BRAVA (I) - 4.000 ptas.

- 264 del $6,60 \%$ de utilidades

Neto 3.736 ,

A cuenta derechos de edición castellana

ESTAMPAS DE LA COSTA BRAVA (II) - 4.000 ptas.

-264 del $6,60 \%$ de utilidades

$$
\text { 19.332,- }- \text { Neto } \frac{3.736 \text {, }}{14.944,}
$$

Queda, por tanto, un saldo a nuestro favor de Ptas. 4.388.- para cuya liquidación espero sus instrucciones.

Reciba los cordiales saludos de su affmo. s. s. y amigo, q. e. s. m.

Firmado: José Zendrera

(verso)

PS/. Por error nos referimos a los contratos de ESTAMPAS DE LA COSTA BRAVA cuando en realidad se trata de ' $u$ [n contrato] "' ${ }_{32}$

\section{8. $(30 / 12 / 1953)$}

[Contracte d'editorial Juventud amb Josep Pla]

"Contrato de edición formalizado el dia 30 de diciembre de 1953 entre Don José Pla, con domicilio en Llofriu, Palafrugell (Mas Pla), (Ilamado en los sucesivo EL AUTOR), por una parte, y Editorial Juventud S.A.,

31. Es tracta de l'impost afegit, l'equivalent a l'actual IRPF

32. Ulegible. 
por otra, con domicilio en Barcelona, calle de Provenza 1or (lamado en los sucesivo EL EDITOR) por el que, en nombre propio y en el de sus herederos y sucesores legales, convienen lo siguiente acerca de la obra ESTAMPAS DE LA COSTA BRAVA, en dos volúmenes, incluyendo las narraciones que se indican al pie del presente contrato. $\mathrm{El}$ segundo volumen podrá llevar el título de ESTAMPAS DEL AMPURDAN.

$I^{\circ}$. El Autor cede al Editor el derecho exclusivo de publicación de la mencionada obra, en lengua castellana, para España y América.

$2^{\circ}$. El Editor abonará al Autor en concepto de derechos el 10\% sobre el precio de venta al público de todos los ejemplares vendidos.

$3^{\circ}$. La liquidación de los derechos de autor se efectuará anualmente, en 31 de diciembre, y deberá ser entregada al Autor y hecho efectivo su importe por el Editor antes de fin de febrero siguiente.

$4^{\circ}$. De todas las ediciones de la obra objeto del presente contrato se deducirán too ejemplares, que no devengarán derechos. Se destinarán 20 al autor y 80 a propaganda y crítica.

$5^{\circ}$. El presente contrato privado puede ser elevado a escritura pública a petición de cualquiera de las partes contratantes, corriendo a cargo del solicitante los gastos que ello ocasione.

$6^{\circ}$. A cuenta de sus derechos, el Autor recibirá a la firma del presente contrato la cantidad de cuatro mil pesetas (Ptas. $4.000,-$ ) por cada volumen.

$7^{\circ}$. Si la obra objeto del presente contrato queda agotada durante un período de seis meses y, previa notificación escrita del Autor, el Editor no publica una nueva edición en los seis meses siguientes, se considerará anulado el presente contrato y revertirán al Autor los derechos por él cedidos.

Firmado, por duplicado y a un solo efecto

El Autor

El Editor

[Després de les firmes hi ha el següent annex:]

Narraciones que integrarán los dos tomos: De COSES VISTES ( $I^{\mathrm{a}}$ serie): 'Pintura de Palamós feta per un meu avantpassat', 'Tardor a Calella de Palafrugell', 'Història de Gervasi', 'Callella, hivern', 'Misèria de Pardal', 'Eternitat', 'Història de Garrau', 'Un de Begur'. - De BODEGó AMB PEIXOS: 'Un viatge frustrat', 'Bodegó amb peixos'. - De PA I RAIM: 'Pa i raïm'. - De VENT DE GARBí: 'Derelictes', 'En mar', 'Vent de garbí' y otras narraciones hasta formar un total de 500 páginas de la 'Biblioteca Selecta' 33 
19. $(31 / 12 / 1953)$

[Carta mecanografiada de Josep Zendrera a Josep Pla]

"3I desembre 1953

Sr. Josep Pla,

Mas Pla,

LLOFRIU (Gerona)

Benvolgut amic:

Ahir vam lliurar a l'amic Tomàs Garcés els contractes de GIRONA ${ }^{34}$ i CARTES DE LLUNY, ${ }^{35}$ tota la documentació relativa a l'existència d'aquest últim llibre i el contracte per a la traducció castellana de dos volums de narracions de vostè que publicaríem sota el títol de ESTAMPAS DE LA COSTA BRAVA (potser el segon podrà dur el títol: ESTAMPAS DEL AMPURDAN). Li prego que ens enviï material d'una extensió de roo pàgines de les del tipus de la 'Biblioteca Selecta ${ }^{36}$ amb temes empordanesos, ja que en els 5 volums de la sèrie 'Coses vistes' només hem trobat material per a unes 400 pàgines de la mida indicada. Penso que li serà fàcil de trobar entre els seus originals unes quantes 'Estampes' més.

En Garcés li farà a mans la carta adreçada a vostè en què li detallo la solució convinguda per a liquidar aquest afer; espero que ho trobarà conforme i que tindrà la bondat de retornar-nos signats els corresponents rebuts i el contracte per als dos volums castellans, indicant també la forma que cregui per eixugar el saldo al nostre favor.

Amb els millors auguris per a l'Any Nou tinc el gust d'enviar-li tres llibres que s'acaben de publicar i que segurament han d'interessar-li: LA ASCENSION AL EVEREST, de John Hunt, SIETE AÑOS EN EL TIBET, de Heinrich Harrer i CON ROMMEL EN EL DESIERTO de H. W. Schmidt.

Cordialment el saluda el seu affm. s. i amic Josep Zendrera."

34. És a dir, el contracte, probablement firmat el 30 d'octubre de 1948, que, segons Zendrera, Pla havia violat en publicar el llibre a Selecta.

35. És a dir, el contracte que havia firmat Pla per a aquest Ilibre, publicat el 1948 . No hem trobat constància a l'arxiu de Joventut d'aquest contracte ni de l'esmentat a la nota anterior, $\mathrm{i}$ això pot voler dir que, efectivament, Zendrera no en va guardar ni la còpia. Tampoc no es troben a l'arxiu de Selecta, parcialment destruït per un incendi.

36. Cf nota 28. 
20. $(5 / 3 / 1954)$

[Carta mecanografiada de Josep Zendrera a Josep Pla]

"5 marzo 1954

Sr. D. José Pla,

Mas Pla,

LLOFRIU (Palafrugell)

Mi distinguido amigo:

Como aclaración al contrato a que se refiere nuestra carta de 30 de diciembre último, ${ }^{37}$ relativa a la traducción castellana de diversas narraciones de COSES VISTES, que se publicarán en dos volúmenes según se detalla en el mismo, he de manifestarle que dicho contrato se refiere a la primera edición de los dos aludidos volúmenes de narraciones, entendiéndose que para la segunda y sucesivas ediciones de dichas obras será preciso que nos pongamos de acuerdo autor y editor acerca de las condiciones de las mismas.

Con este motivo, me reitero de Vd. affmo. s. y amigo,

q. e. s. m.,

José Zendrera."

2I. $(23 / 3 / 1954)$

[Carta mecanografiada de Josep Zendrera a Josep Pla]

"23 març 1954

Sr. Josep Pla,

Mas Pla,

LLOFRIU (Gerona)

Distingit amic:

El Sr. Garcés va donar-nos els tres rebuts - dos d'ells corresponents a l'anticip pels drets de l'edició castellana d'ESTAMPAS DE LA COSTA BRAVA, dos volums, i l'altre rebut corresponent a la totalitat dels drets de l'edició castellana de CADAQUÉs-, així com el contracte relatiu a ESTAMPAS DE LA COSTA BRAVA..$^{8}$ Així que es publiqui el seu llibre CONTRABAN ${ }^{39}$ completarem el material que ens falta per als volums de les ESTAMPAS.

Avui hem lliurat a la Casa del Libro, ${ }^{40}$ per compte de vostè, 674 exemplars relligats de CARTES DE LLUNY i 998 en rama. ${ }^{41}$ La liquidació, segons les condicions convingudes, és doncs la següent:

37. Z_17_30/12/1953.

38. Z_18_30/12/1953.

39. Sobre Contraban, cf. nota 40.

40. Era la seu d'Editorial Selecta. 
Existencias CARTES DE LLUNY:

Càrrecs

Abonaments

998 exs. rama, a 13,50

$674 "$ rell., a $14,-$

Rebaixa del $15 \%$
13.473,00

$9.436,00$

22.909,00

$3.436,35$

$19 \cdot 472,65$

Drets edició castellana CADAQUÊS

(8.00o pts. menys $\$ 28$,- d'utilitats)

$7 \cdot 472,-$

A compte drets edició castellana

ESTAMPAS DE LA COSTA BRAVA

(8.00o ptes. pels dos volums,

menys 528,-d'utilitats)

7.472,-

$19.472,65$

14.944,-

La liquidació del saldo al nostre favor, de Ptes. 4.528,65, potser fóra més còmode per vostè i per nosaltrés fer-la a través de l'Editorial Selecta. Aixi ho he indicat a l'amic Garcés.

Cordialment el saluda el seu affm. s. i amic

J. Zendrera"

22. $(5 / 9 / 1954)$

[Carta mecanografiada de l'editorial Joventut a Josep Pla]

"s septiembre 1957

Sr. D. José Pla,

Mas Pla,

LLOFRIU - Palafrugell (Gerona)

Muy señor nuestro:

Nos es grato comunicarle que de acuerdo con lo establecido en el contrato de edición de fecha zo de diciembre de 1953, acabamos de publicar el primer tomo de 'Estampas de la Costa Brava', el cual lleva por título COSAS DEL MAS (sic) Y DE LA COSTA BRAVA. De este primer tomo se ha hecho una tirada de 3.036 ejemplares y su precio de venta es de 60 ptas.

41. Per a aquestes xifres, vegeu $Z_{-} 16 \_3 / 6 / 1953$. Entre el 3 de juny de 1953 i el 23 de març de 1954 s'havien venut $680-674=6$ exemplars. 
Con fecha 2 del actual, por correo certificado, le hemos enviado los 20 ejemplares de autor. ${ }^{2}$

El segundo tomo, que llevará por título HISTORIAS DEL AMPURDÁN, se pondrá a la venta el próximo mes, ${ }^{43}$

Aprovechamos esta oportunidad para reiterarnos de Vd. affmos. ss. ss. q. e. s. m."

23. $(24 / 7 / 1963)$

[Carta mecanografiada sense firmar de Josep Zendrera a Josep Pla] "24 juliol 1963

Sr. Josep Pla,

Mas Pla,

PALAFRUGELL (Gerona)

Distingit amic:

Un tal senyor André de Riano ens proposa de publicar, en francès o en anglès, el seu llibre CADAQUÉS. La carta ve des de Nova York.

En principi la idea ens sembla aceptable (sic) i li agrairem que ens contesti tot seguit per poder donar una ràpida resposta al senyor Riano.

En espera de les seves notícies, rebi una afectuosa salutació del seu amic,"

\section{4. $(31 / 7 / 1963)$}

[Carta mecanografiada, sense firmar de l'editorial Joventut a Josep Pla] " 31 juliol 1963

Sr. Josep Pla,

Mas Pla,

LLOFRIU, prov. Girona.

Distingit amic:

Estem fent gestions per la publicació en francès i anglès de la seva obra CADAQUES, editada per nosaltres.

Abans de tancar cap tracte en aquest sentit, desitgem tenir la conformitat de vostè. Naturalment, els drets de traducció serien cedits a Editorials solvents. Si s'arribés a un acord per la publicació d'aquestes edicions estrangeres, la comissió que deduiríem per la nostra gestió seria

42. La còpia de la carta va acompanyada de Palbarà corresponent, datat a zo d'agost de 1957 i firmat "autor" amb una lletra que pot correspondre's a la de Pla.

43. Un albarà, datat a l'1 d'octubre del mateix any 1957 , certifica el lliurament de 20 exemplars de Historias del Ampurdân, i també va firmat "autor", 
el $30 \%$ de les quantitats que es cobressin en concepte de drets d'autor. Esperant les seves ordres, el saludem cordialment."

25. $(6 / 9 / 1963)$

[Carta mecanografiada de Josep Zendrera a Josep Pla]

"6 septiembre 1963

Sr. D. José Pla,

LLOFRIU (Prov. de Gerona)

Amigo Pla:

Estuve hace unos días en Calella y tenía el propósito de ir a verle a Llofriu, pero no pude hacerlo por haber "pescado" allí un fuerte enfriamiento. Quería hablarle de las nuevas edicions del CADAQUÉS, catalán y castellano. El catalán está agotándose (me quedan unos cien ejemplares que tengo en Cadaqués y que se van vendiendo allí). ${ }^{44}$ Ahora quería poner a la venta la edición castellana que ha traducido nuestro común amigo José Roc; haría una edición de unos 1.500 ejemplares que espero poder vender al precio de 60 pesetas. 45

Espero su conformidad para dar la orden de impresión. A usted le corresponderían como derechos de autor 9.000 pesetas, que le remitiría en cheque o ingresaría en el Banco que usted me diga.

En cuanto a la edición catalana, creo que podremos hacerla el año que viene.

Espera sus noticias su afectísimo amigo,

José Zendrera"

\section{6. $(19 / 10 / 1963)$}

[Carta mecanografiada de Josep Zendrera a Josep Pla]

"is octubre 1963

Sr. D. José Pla,

Mas Pla,

LLOFRIU (Gerona)

Amigo Pla:

Refiriéndome a mi carta del 6 de septiembre último, he de comunicarle que al puntualizar nuestro departamento de Contabilidad lo relati-

44. La tirada de Cadaqués en cacalà era de 2,100 (document 2). Aixó vol dir que en 16 anys se n'han venut uns 2.000 (cal tenir en compte els exemplars de promoció, d'autor, etc.).

45. Cadaqués. Trad. Josep Roch. Otros libros de viajes. Barcelona: Juventud, 1964. 70 pàgines. Tirada de 2.048 exemplars. L'any 1982 es va reeditar: 3.000 exemplars. 
vo a los derechos de autor de la edición castellana de su obra CADAQUEES, resulta que en 30 de diciembre de 1953 se le liquidaron ya estos derechos correspondientes a una edición de 2.000 ejemplares, como consta en el recibo cuya fotocopia le adjunto.

Queda, pues, aclarado este extremo y rectificado lo que sobre el mismo lé indiqué en mi carta anterior.

Reciba los cordiales saludos de su affmo. amigo,

José Zendrera."

27. $(13 / 3 / 1980)$

[Carta mecanografiada de Marià Manent a Josep Pla]

"Sr.

Josep Pla,

Mas Pla,

LLOFRIU - PALAFRUGELL

Prov. Girona

13 març 1980

Estimat amic:

Vaig estar molt content de poder-vos acompanyar ahir al dinar d'homenatge. Per molts anys!

En Vergés ${ }^{46}$ em va donar, per indicació vostra, la liquidació de drets de les vostres obres COSAS DEL MAR Y DE LA COSTA BRAVA I HISTORIA DEL AMPURDÁN. Us la torno a enviar amb aquestes ratles, perquè la guardeu en el vostre arxiu. També incloc el rebut corresponent, pregant-vos que ens el torneu firmat. La quantitat de $2.575,-$ ptes. us va ser enviada per gir postal. Suposo que ja us haurà arribat.

Una cordial abraçada del vostre vell amic.

Marià Manent."

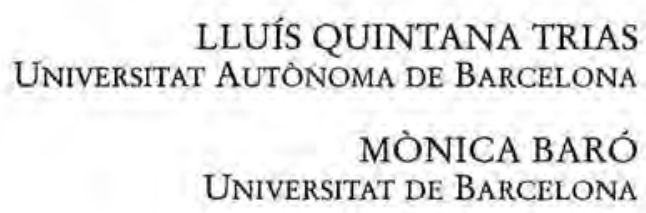

46. Josep Vergés era el propietari de l'editorial Destino, on Pla s'havia definitivament instal lat des de meitats dels anys 60 . 


\section{ANNEX I}

Edicions entre 1940 i 1950. (Gustà, “Josep Pla”), (Palau i Dolcet), (Manent, Tres escritores)

\begin{tabular}{|c|c|c|c|}
\hline $\begin{array}{l}\text { Títol ( cursiva: castellà; } \\
\text { cursiva negreta: català) }\end{array}$ & Editorial & Any & Comentari \\
\hline $\begin{array}{l}\text { Historia de la II Rep Esp } \\
\text { ( } 4 \text { vol.) }\end{array}$ & Destino & $1940-194 \mathrm{I}$ & \\
\hline $\begin{array}{l}\text { Costa Brava. } \\
\text { Guia general y veridica }\end{array}$ & Destino & I94I & \\
\hline Rusiñol y su tiempo & Destino & 1942 & \\
\hline Las ciudades del mar & Argos & 1942 & \\
\hline Viaje en autobús & Destino & 1942 & $\begin{array}{l}\text { Es reedita el } 1943 \mathrm{i}, \text { amb } \\
\text { variants, el } 1948 .\end{array}$ \\
\hline Humor honesto y vago & Destino & 1942 & \\
\hline El pintor Joaquín Mir & Destino & 1944 & \\
\hline Guía de la Costa Brava & Destino & 1945 & $\begin{array}{l}\text { 2a. edició de Costa Brava } \\
\text { amb variants. 1948: } 3 a \text {, ed. }\end{array}$ \\
\hline Un señor de Barcelona & Destino & 1945 & Es reedita el mateix any \\
\hline La huida del tiempo & Destino & 1945 & \\
\hline Viatge a Catalinya & Áncora & 1946 & \\
\hline Cartes de lluny & Aigua Blava & 1946 & Edició de bibliòfil. \\
\hline Cadaqués & Joventut & 1947 & \\
\hline Vida de Manolo & Destino & 1947 & \\
\hline Cartes de lluny & Joventut & 1948 & $\begin{array}{l}\text { Reedició de } 1946 \mathrm{amb} \\
\text { variants }\end{array}$ \\
\hline Coses vistes & Selecta & 1949 & $\begin{array}{l}\text { El mateix any en fa una } \\
\text { edició de bibliófil } \\
\text { (Ed. Montcal) }\end{array}$ \\
\hline Viaje a pie & Destino & 1949 & \\
\hline $\begin{array}{l}\text { Guía de Mallorca, } \\
\text { Menorca e Ibiza }\end{array}$ & Destino & 1950 & \\
\hline
\end{tabular}




\section{ANNEX 2}

Tiratges, avançaments, preus i vendes. Entre parèntesi, font d'on es treu la informació $(\mathrm{C}=$ correspondència amb Cruzet; $\mathrm{Z}=$ correspondència amb Zendrera)

\begin{tabular}{|c|c|c|c|c|c|}
\hline $\begin{array}{l}\text { Llibre (data } \\
\text { aprox. edició) }\end{array}$ & Tiratge & $\begin{array}{l}\text { Avançament } \\
\text { (ptes.) }\end{array}$ & Preu (ptes.) & $\%$ & Venuts \\
\hline $\begin{array}{l}\text { Cadaqués } \\
(4 / 1947)\end{array}$ & $\begin{array}{l}2.100 \\
\left(Z_{-2} 7 / 9 / 1948\right)\end{array}$ & $\begin{array}{l}8.000 \\
\left(Z_{-16 / 1 / 1947)}\right.\end{array}$ & 40 & 10 & $\begin{array}{l}2.000 \\
\left(Z \_6 / 9 / 1963\right)\end{array}$ \\
\hline $\begin{array}{l}\text { Cartes de lluny } \\
\left(\mathrm{I} / \mathrm{I} 94^{8}\right)\end{array}$ & $\begin{array}{l}2.000 \\
\left(Z_{-3 I} / 12 / 195 \mathrm{I}\right)\end{array}$ & 8.000 & & & $\begin{array}{l}210 \\
\left(Z_{-31 / 12 / 1951)}\right. \\
322\left(Z_{-3} / 6 / 1953\right) \\
\end{array}$ \\
\hline $\begin{array}{l}\text { Cosas del mar y } \\
\text { de la Costa Brava } \\
(9 / 1957)\end{array}$ & $\begin{array}{l}3.036 \\
\left(Z_{-5} / 9 / 1957\right)\end{array}$ & $\begin{array}{l}4.000 \\
\left(\mathrm{Z} \_30 / 12 / 1953\right)\end{array}$ & $\begin{array}{l}60 \\
\left(Z_{5} / 9 / 1957\right)\end{array}$ & I0 & \\
\hline $\begin{array}{l}\text { [estàndard Selecta] } \\
\left(C_{-22 / 3 / 1947)}\right.\end{array}$ & 2.000 & 6.000 & $\begin{array}{l}45 \text { (pell) } \\
\text { i } 25 \text { (tela) }\end{array}$ & 10 & \\
\hline $\begin{array}{l}\text { Coses vistes } \\
(9 ? / 1949)\end{array}$ & $\begin{array}{l}3.000 \\
\left(C \_1 / 12 / 1948\right)\end{array}$ & 5.000 & $\begin{array}{l}30 \\
\left(C_{-11} / 3 / 1952\right)\end{array}$ & & $\begin{array}{l}1.200 \\
\left(C \_8 / 3 / 1952\right)\end{array}$ \\
\hline $\begin{array}{l}\text { Bodegó amb peixos } \\
\text { (II/1950) }\end{array}$ & 3.000 & & $\left(\mathrm{C} \_\mathrm{II} / 3 / \mathrm{I} 952\right)$ & & $\begin{array}{l}1.200 \\
\left(C \_8 / 3 / 1952\right)\end{array}$ \\
\hline $\begin{array}{l}\text { L'illa dels } \\
\text { castanyers } \\
(4 / \text { igso) }\end{array}$ & 3.000 & $\begin{array}{l}5.000 \text { més } \\
\text { destrucció } \\
\text { d'exemplars } \\
\left(C_{-4 / 12 / 1950)}\right. \\
\end{array}$ & $\begin{array}{l}30 \\
\left(C \_11 / 3 / 1952\right)\end{array}$ & & $\begin{array}{l}1.100 \\
\left(C \_8 / 3 / 1952\right)\end{array}$ \\
\hline $\begin{array}{l}\text { Pa i Raïm } \\
\text { (7/1951) }\end{array}$ & & & $\left(\mathrm{C} \_11 / 3 / 1952\right)$ & & $\begin{array}{l}1.000 \\
(C+8 / 3 / 1952)\end{array}$ \\
\hline $\begin{array}{l}\text { Un senyor de } \\
\text { Barcelona }(\mathrm{n} / \mathrm{1} / \text { S51 })\end{array}$ & & & $\left(\mathrm{C} \_\right.$.11/3/1952) & & $\begin{array}{l}700 \\
\left(C_{2} 20 / 1 / 1952\right)\end{array}$ \\
\hline $\begin{array}{l}\text { El carrer estret } \\
(\mathrm{I} 2 / 195 \mathrm{I})\end{array}$ & & $\begin{array}{l}4.000 \\
\left(\mathrm{C} \_6 / 9 / 195 \mathrm{I}\right)\end{array}$ & $\left(C_{-}{ }^{3} / 3 / 3 / 1952\right)$ & & $\begin{array}{l}1.000 \\
(20 / 1 / 1952)\end{array}$ \\
\hline $\begin{array}{l}\text { Girona } \\
(10 / 1952)\end{array}$ & $\begin{array}{l}2.500 \\
\left(C_{-} 18 / 9 / 1952\right)\end{array}$ & $\begin{array}{l}2.000 \\
\left(Z_{5} / 12 / 1952\right) \\
5.000 \\
\left(C_{11} / 9 / 1952\right)\end{array}$ & & & $\begin{array}{l}1.300 \\
\left(C_{-1} / 12 / 1952\right)\end{array}$ \\
\hline $\begin{array}{l}\text { Els pagesos (2a) } \\
(1952)\end{array}$ & $\begin{array}{l}2.000 \\
\left(C_{-3} / 10 / 1952\right)\end{array}$ & $\begin{array}{l}3.000 \\
\left(C_{-3} / 10 / 1952\right)\end{array}$ & ${ }^{30}\left(\mathrm{C} \_11 / 3 / 1952\right)$ & & \\
\hline
\end{tabular}




\section{ANNEX 3}

\begin{tabular}{|l|l|}
\hline Cosas del mar y de la Costa Brava & Volums originals d'Ed. Selecta \\
\hline El coral y los coralerós & Contraban (1954) \\
\hline $\begin{array}{l}\text { Pintura de Palamós hecha } \\
\text { por un antepasado mio }\end{array}$ & Coses vistes (1949) \\
\hline Uno de Bagur & Coses vistes (1949) \\
\hline Bodegón con peces & Bodegó amb peixos (1950) \\
\hline Viento lebeche & El vent de garbi (1952) \\
\hline En el mar & El vent de garbi (1952) \\
\hline Historias de buques hundidos & El vent de garbi (1952) \\
\hline & \\
\hline Historias del Ampurdán & Coses vistes (1949) \\
\hline Otoño en Calella de Palafrugell & Coses vistes (1949) \\
\hline Calella, invierno & Coses vistes (1949) \\
\hline Miseria de Pardal & Coses vistes (1949) \\
\hline Eternidad & Coses vistes (1949) \\
\hline La historia de Gervasio & Coses vistes (1949) \\
\hline Historia de Carrau & Coün (1951) \\
\hline Contrabando & $1954)$ \\
\hline
\end{tabular}




\section{REFERÈNCIES}

GALLOFRÉ I VIRGILI, Maria Josepa. L'edició catalana i la censura franquistal 1939-195s. Barcelona: Publicacions de l'Abadia de Montserrat, 2003.

Gallofré Virgili, Maria Josepa. "Amb les pedres disperses". Josep M. Cruzet i Josep Pla. Amb les pedres disperses, Cartes 1946-1962 Ed. Maria Josepa Gallofré Virgili. Barcelona: Destino, 2003. 7-29. GuSTÀ, Marina. Els orígens ideològics i literaris de Josep Pla. Barcelona: Curial, 1995.

-. "Josep Pla". Història de la Literatura Catalana. Ed. Joaquim Molas. Vol. 10. Barcelona: Ariel, 1987. 129-90.

MANENT, Albert. "Els llibres de bibliòfil en català", Miscel-lània Joan Gili. Ed. Albert Manent i Josep Massot i Muntaner. Barcelona: Publicacions de l'Abadia de Montserrat, 1988. 321-60.

- Tres escritores catalanes: Carner, Riba, Pla. Madrid: Gredos, 1973.

- Del noucentisme a l'exili. Sobre cultura catalana del nou-cents. Barcelona: Publicacions de l'Abadia de Montserrat, 1997.

PALAU Y DOLCET, Antonio. Manual del librero hispanoamericano. Barcelona: Librería Palau, 1948-77.

PLA, Josep, i Josep M. Cruzet. Amb les pedres disperses. Cartes $1946-$ 1962. Edició i pròleg de Maria Josepa Gallofré Virgili. Barcelona: Destino, 2003.

QuiNTANa TRIAS, Lluís. "Josep Pla a la peninsula del Cap de Creus: la creació d'un cronòtop". Bulletin of Hispanic Studies 81.4 (2004): $571-84$.

-. "Un manuscrit de Josep Pla per a la tercera edició de Cartes de lluny". Estudis romànics XXV (2003): 279-94.

X. "Editorial 'Ancora' edita libros catalanes". Destino is febr. 1947). 